\title{
Chemical composition and antinociceptive effects of essential oil from aerial parts of Gundelia tournefortii $L$ Asteraceae (Compositae) in rats
}

\author{
Esam Qnais ${ }^{1,3 *}$, Yousra Bseiso', Mohammad Wedyan', Maryam Al-Omari' ${ }^{2}$, \\ Hakam Alkhateeb ${ }^{2}$ \\ ${ }^{1}$ Department of Biology and Biotechnology, Faculty of Science, Hashemite University, Zarka, ${ }^{2}$ Faculty of Medicine, Yarmouk \\ University, Irbid, ${ }^{3}$ Department of Medical Laboratories, Faculty of Health Sciences, American University of Madaba, Madaba, \\ Jordan
}

*For correspondence: Email: Esam_11@hotmail.com, Esamqn@hu.edu.jo; Fax: 00962-53826368

\begin{abstract}
Purpose: To investigate the antinociceptive effect of the essential oil from the aerial parts of Gundelia. tournefortii (EOGT) in various experimental models

Methods: The essential oil from the aerial parts of Gundelia tournefortii was extracted using steam distillation method median lethal dose (LD50) of EOGT was evaluated using the method of Lorke. Antinociceptive effect of EOGT in rats was carried out using chemical (formalin and acetic acid) and thermal (hot-plate) nociceptive tests at doses of 10, 31.6, 100, 316 and $1000 \mathrm{mg} / \mathrm{kg}$. The possible mechanism of action of EOGT was also examined.

Results: In acute toxicity test, LD 50 for EOGT was $2500 \mathrm{mg} / \mathrm{kg}$. EOGT at test doses (10, 31.6, 100, 316 and $1000 \mathrm{mg} / \mathrm{kg}$, orally) significantly reduced pain response in all tests in a dose-dependent manner $(p<0.05)$. Glibenclamide (potassium channel sensitive to ATP antagonist) and yoimbina ( $\alpha 2$ adrenergic receptor antagonist), partially antagonized the antinociceptive activity induced by EOGT. However, naloxone (opioid antagonist) and L-NAME (an inhibitor of nitric oxide synthase) did not reverse the antinociception produced by EOGT.

Conclusion: Essential oil from the aerial parts of G. tournefortii shows significant antinociceptive activity, which appeared to involve the participation of $K^{+}$channels sensitive to ATP and adrenergic receptors. These findings justify in part the traditional use of the plant in the treatment of various painful conditions.
\end{abstract}

Keywords: Antinociceptive, Opioid receptors, Adrenergic receptor, Essential oil, Gundelia tournefortii, Formalin test

Tropical Journal of Pharmaceutical Research is indexed by Science Citation Index (SciSearch), Scopus, International Pharmaceutical Abstract, Chemical Abstracts, Embase, Index Copernicus, EBSCO, African Index Medicus, JournalSeek, Journal Citation Reports/Science Edition, Directory of Open Access Journals (DOAJ), African Journal Online, Bioline International, Open-J-Gate and Pharmacy Abstracts

\section{INTRODUCTION}

Gundelia tournefortii L. commonly known in our region as "Akub", is a member of the Asteraceae (Compositae) family which grows in the semidesert area of Jordan and the Mediterranean areas including Palestine, Syria and Iraq during late winter and early spring. Gundelia tournefortii
$L$ is a spiny perennial herb thistle that is consumed as a fresh or cooked artichoke-like vegetable [1]. In Jordan Akub is sold along highways in the Northern part of the country as well as stores in Amman. Gundelia tournefortii is usually employed in traditional medicines as a remedy to treat liver diseases, diabetes, chest pain, inflammation, gastric pain, vitiligo, diarrhea 
and bronchitis [2-5]. In addition, G. tournefortii reduces fat and cholesterol content of the blood and is believed to have hypoglycemic and laxative properties [6]. In Turkey, it is proposed to enhance gingiva's and used as an appetizer [7].

Phytochemical studies carried out with Gundelia tournefortii have demonstrated the occurrence of many classes of constituents, including phenols, glycosides, tannins, flavonoids, carbohydrate, alkaloids, nitrate, and saponins [8]. Five known compounds (scopoletin, isopoletin, esculin and a mixture of $ß$-sitosterol and stigmasterol) were isolated and identified from $G$. tournefortii. Furthermore, several essential oils from the aerial parts of $G$. tournefortii were identified by GC-MS analysis with terpinyl acetate, methyl eugenol, $\beta$-caryophyllene, thymol, $p$-cymene and $\mathrm{y}$-terpinene as the major oil components [9].

Several studies have demonstrated that Gundelia tournefortii has pharmacological properties such as antibacterial activity [6], antiplatelet activity [2], hepato-protective activity [10], hypolipemic activity [11], antioxidant activity [5], hypoglycemic activity [11], antiparasite activity, and anti-inflammatory activity [12]. Gundelia tournefortii also reduces some cardiovascular risk factors and decrease atherosclerosis $[6,13]$.

Considering the popular use and because of the scarcity of pharmacological studies on the antinociceptive activity, this study investigated the chemical composition and antinociceptive activity as well as some of the possible mechanisms that underlie the antinociceptive action of the essential oil extract of Gundelia tournefortii.

\section{EXPERIMENTAL}

\section{Plant material}

Aerial parts of Gundelia tournefortii were collected during March to April period of 2015 from Arbid (Jordan). The plant material was identified and authenticated by Associate Professor Yasen Zakaria, a taxonomist at Department of Biology. A voucher specimen was deposited under the number HU-2014-466 at the Hashemite University herbarium, Zarka, Jordan, for future reference.

\section{Determination of essential oil composition}

The essential oil from the dried aerial parts of Gundelia tournefortii was obtained by hydrodistillation for $8 \mathrm{~h}$ using a Clevenger-type apparatus according to Siani et al [14]. The essential oil of Gundelia tournefortii was performed by GC on a Trace GC ULTRA with FID detector gas chromatograph equipped with a column (30 m x $0.25 \mathrm{~mm} \times 0.25 \mu \mathrm{m})$ type VB-5 (methylpolysiloxane with $5 \%$ of phenyl) and split injection. Mass spectrometry (MS) analysis was performed on a Polaris Q MS mass spectrometer (with an ion-trap at $70 \mathrm{eV}$ ). Column temperatures were programmed from $40^{\circ} \mathrm{C}$ for $2 \mathrm{~min}$, raised to $180{ }^{\circ} \mathrm{C}$ at $4^{\circ} \mathrm{C} \cdot \mathrm{min}^{-1}$. Helium was the carrier gas at $1.4 \mathrm{~mL} / \mathrm{min}$. The identification of volatile constituents of the essential oil (EO) was made by automated comparison of their mass spectra with that of the NIST (National Institute of Standards and Technology) library.

\section{Drugs and chemicals}

All chemicals and drugs were purchased from Sigma Chemical Co., St. Louis, MO, unless otherwise stated. All drugs were dissolved in sterile saline. The essential oil was prepared in 1 $\%$ v/v Tween 80 in sterile saline.

\section{Experimental animals}

Non-fasting male Wistar rats weighing between $150-250 \mathrm{~g}$ or Swiss albino mice weighing between 25 - $35 \mathrm{~g}$ (only for acute toxicity experiment) were used. The animals were obtained from the Animal House, Department of biology, Faculty of Basic Sciences, Hashemite University. The animals were kept in an Animal House provided with a $12 \mathrm{~h}$ light/dark cycle at 22 - $25{ }^{\circ} \mathrm{C}$ and free access to food and water ad libitum. All test solutions were administered in a volume of $10 \mathrm{ml} / \mathrm{kg}$ body weight. The animals were allowed to adapt to the laboratory for at least $2 \mathrm{~h}$ before testing and were used only once. Animal care and handling procedure were in accordance with the International Association for the Study of Pain guidelines for the use of animals in pain research [15]. Experimental protocols and procedures were approved by Research Ethics Committee of Hashemite University (approval ref. no. 154/342/2015).

\section{Hot-plate test}

The hot-plate test at $50 \pm 1{ }^{\circ} \mathrm{C}$ was used as previously described by Qnais et al [16]. Latency to a discomfort reaction (licking paws) was determined in seconds before and 60 min after oral administration of vehicle (1\% v/v Tween 80 in sterile saline), EOGT (10, 31.6, 100, 316 and $1000 \mathrm{mg} / \mathrm{kg}$ ) to 6 groups of male rats, (six animals per group). The 7 th group received morphine intraperitoneally $(5 \mathrm{mg} / \mathrm{kg}$; positive control). The largest doses were determined on 
the basis of $L D_{50}$ experiments. The doses were calculated to be located at approximately $0.5 \mathrm{log}$ units from each other on a log scale. The cut-off time was $60 \mathrm{~s}$. The prolongation of the latency times was compared to the values of the control and used for statistical comparison. Baseline was considered as the mean of three readings of the reaction time obtained before administration of vehicle, EOGT or morphine and was defined as the normal reaction time of animals to this temperature. The increase over baseline (\%) was calculated using Eq 1.

Increase $(\%)=\{(A-B) / B\} 100$

where $A$ is the mean of three readings of reaction time after treatment taken within $5-7$ min; $B$ is the mean of three readings of reaction time obtained before treatment. In this, and the following experiments, the inhibitory dose $50 \%$ $\left(\mathrm{ID}_{50}\right)$ was determined from the plot of individual experiments by the best visual fit.

\section{Acetic acid-induced abdominal writhing test}

This test was performed in rats as described by Matheus et al [17].Briefly, after an intraperitoneal administration of a $2 \%(\mathrm{v} / \mathrm{v})$ acetic acid solution in a volume of $0.1 \mathrm{ml} / 10 \mathrm{~g}$ body weight. The nociceptive behavior was quantified by counting the number of writhes, a response consisting of contraction of an abdominal wall, pelvic rotation followed by hind limb extension, during continuous observation for $20 \mathrm{~min}$ beginning from $5 \mathrm{~min}$ after the acetic acid injection. Rats were orally pre-treated $60 \mathrm{~min}$ before the administration of the nociceptive agent with EOGT $(10,31.6,100,316$ and $1000 \mathrm{mg} / \mathrm{kg}$ ), or vehicle (1\% Tween 80 in normal saline). A positive control group was composed of animals pre-treated with morphine (5 mg/kg, i.p.). Inhibitions of writhing was computed using Eq 2.

Inhibition $(\%)=\{(\mathrm{N}-\mathrm{Nt}\} / \mathrm{N}\} 100$

where $\mathrm{N}$ is the mean number of stretching of control group and $\mathrm{Nt}$ is the mean number of stretching of test group.

\section{Formalin test}

Rats were divided into groups (six rats each) and were injected orally with either vehicle (1\% v/v Tween 80 in sterile saline) or EOGT $(10,31.6$, 100,316 and $1000 \mathrm{mg} / \mathrm{kg}$ ). A positive control group was composed of animals pre-treated with morphine (5 mg/kg, i.p.). Sixty min later, $50 \mu \mathrm{L}$ of $5 \%$ formalin was injected subcutaneously into the dorsal surface of the right hind paw of each rat using a microsyringe with a 27 gauge needle.
Immediately after formalin injection, animals were placed individually in acrylic observation chambers $\left(320 \mathrm{~cm}^{2} \times 40 \mathrm{~cm}\right)$. Mirrors were arranged at angles to allow clear observation of the paws of the animals. Licking of the injected paw was defined as the nociceptive response. The total time of the response was measured during the periods of $0-5$ min (early phase) and $15-40$ min (late phase). Inhibition of licking (\%) was calculated using Eq 3.

Inhibition $(\%)=\{(A-B) / A\} 100$

where $\mathrm{A}$ is the time of licking before treatment; $\mathrm{B}$ is the time of licking after treatment.

\section{Determination of possible mechanisms of antinociceptive action}

In order to evaluate the possible participation of opioid system, potassium channels sensitive to ATP, adrenergic system, and nitric oxide pathways in the antinociceptive action of EOGT, the animals pre-treated with antagonist naloxone (10 $\mathrm{mg} / \mathrm{kg}$ ), glibenclamide (2 mg/kg), yoimbina (1 $\mathrm{mg} / \mathrm{kg}$ ), and L-NAME (3 $\mathrm{mg} / \mathrm{kg}$ ), respectively. Antagonists were administered i.p. 15 min before oral administration of vehicle (1\% v/v Tween 80 in sterile saline) or the ED50 of EOGT. Using the acetic acid-induced abdominal writhing test, hotplate test, and the formalin test as described above, inhibition of the writhing response, latency times and licking was calculated after $60 \mathrm{~min}$ of vehicle (1\% v/v Tween 80 in sterile saline) or EOGT administration.

\section{Acute toxicity test}

Lethal dose $\left(L_{50}\right)$ of the EOGT was evaluated in mice as described by Lorke [18]. Animals were randomly assigned to different groups containing 5 mice in each group. EOGT $(10,100,1000$, 2000, 3000 and $5000 \mathrm{mg} / \mathrm{kg}$ ) was administered orally to six groups of mice, and the control group received $1 \% \mathrm{v} / \mathrm{v}$ Tween 80 in sterile saline, (10 $\mathrm{ml} / \mathrm{kg}$ ). The mice were allowed food and water ad libitum. Signs of toxicity and mortality within $72 \mathrm{~h}$ were recorded.

\section{Statistical analysis}

The data obtained are presented as mean \pm SEM, and were analyzed using GraphPad Prism. Statistically significant differences between groups were calculated by the application of oneway analysis of variance (ANOVA) followed by Duncan's test for multiple comparisons. $P<0.05$ was chosen as the criterion of statistical significance. 


\section{RESULTS}

\section{Essential oil}

A total of 18 compounds, representing $88.4 \%$ of the total oil content were identified (Table 1). $\alpha$ Terpinyl acetate (15.2\%), eugenol (9.5\%), pcyme $(9.5 \%), \quad \beta$-caryophyllene $(7.1 \%)$, and estragole $(6.1 \%)$, were the major constituents (Table 1).

Table 1: Constituents of essential oil of aerial parts of Gundelia tournefortii

\begin{tabular}{|c|c|}
\hline Constituent & $(\%)$ \\
\hline$\alpha$-Tujone & 4.1 \\
\hline a-Humulene & 2.1 \\
\hline p-Cyme & 9.5 \\
\hline$\beta$-Caryophyllene & 7.1 \\
\hline a-Farnesene & 2.1 \\
\hline Estragole & 6.1 \\
\hline Thymol & 4.1 \\
\hline Cuminal & 3.2 \\
\hline a-Pinene & 3.5 \\
\hline$\beta$-Elemene & 1.4 \\
\hline Spathulenol & 1.2 \\
\hline Eugenol & 9.5 \\
\hline Geranial & 2.7 \\
\hline Carvacrol & 3.1 \\
\hline Linalool & 4.5 \\
\hline Neral & 4.9 \\
\hline$\alpha$ - Pinena & 4.1 \\
\hline$\alpha$-Terpinyl acetate & 15.2 \\
\hline Total identified & 88.4 \\
\hline
\end{tabular}

\section{Acute toxicity}

The $\mathrm{LD}_{50}$ of the EOGT in mice was $2500 \mathrm{mg} / \mathrm{kg}$ indicating a low toxicity of the EOGT. No signs of toxicity, such as diarrhoea, motor impairment, ataxia, hyperactivity or alterations on respiratory frequency or piloerection, were noted in the control or experimental animals at lower doses. Also, no gastric ulcerogenic effect was observed in controls or treated animals. Severe depression, abnormal gait, ataxia, increased respiration and decreased activity were observed at dose higher than $3000 \mathrm{mg} / \mathrm{kg}$

\section{Effect of EOGT on latency time}

In hot plate test, EOGT (10, 31.6, 100, 361 and $1000 \mathrm{mg} / \mathrm{kg}$, orally) significantly increased latency (time of response) to thermal stimulation in a dose-dependent manner compared with control (vehicle only) rats with $\mathrm{ID}_{50}$ value of 52.1 $\pm 3.2 \mathrm{mg} / \mathrm{kg}$ (Fig. 1). The percentage of increase in baseline produced by morphine ( $5 \mathrm{mg} / \mathrm{kg}$, i.p.) was $85.1 \pm 3.1 \%$.

\section{Effect of EOGT on acetic acid-induced abdominal writhing}

The antinociceptive effect of EOGT on the writhing are shown in Figure 2. Administration of the EOGT orally at different doses $(10,31.6,100$, 361 and $1000 \mathrm{mg} / \mathrm{kg}$ ) caused an inhibition of the writhing response induced by acetic acid compared with control rats (vehicle only) ( $p<$ 0.05). This inhibition was dose-dependent. The calculated mean $\mathrm{ID}_{50}$ value was $81.1 \pm 2.4$ $\mathrm{mg} / \mathrm{kg}$. The percentage inhibitions of writhing produced by morphine (5 $\mathrm{mg} / \mathrm{kg}$, i.p.) was $91.3 \pm$ $2.1 \%$.

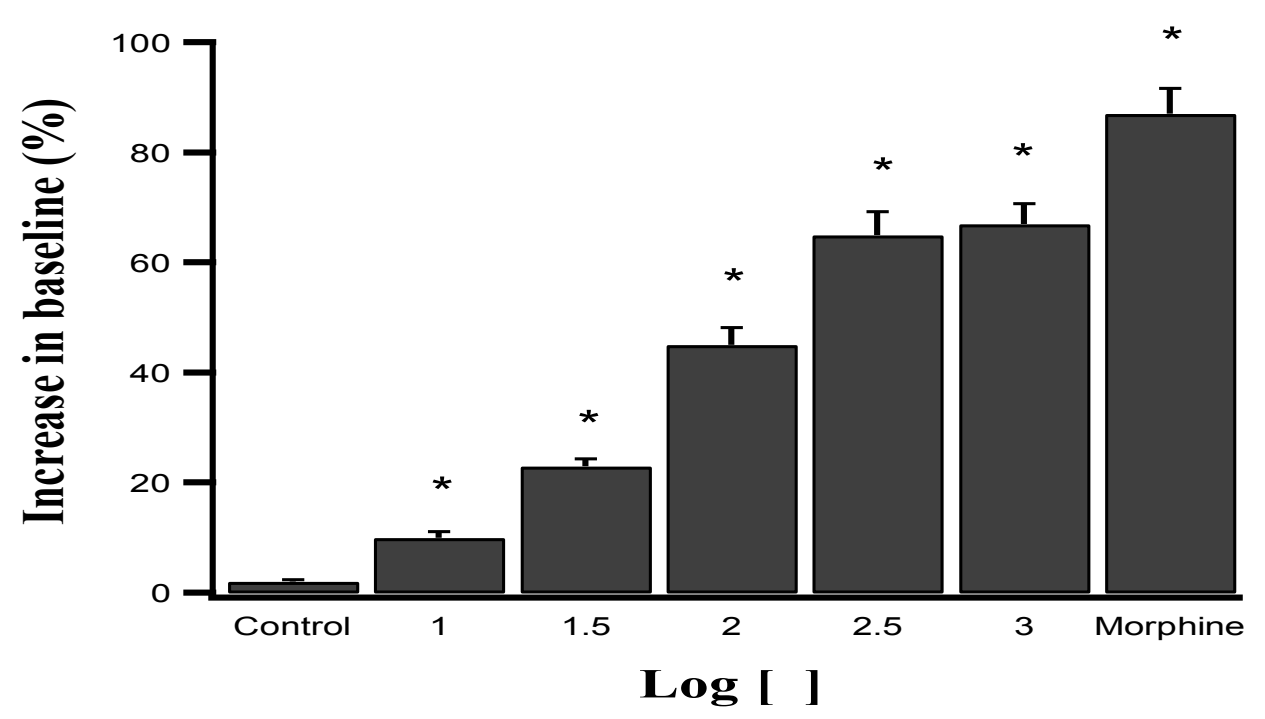

Figure 1: Effect of EOGT and morphine administration on the thermal nociception in rats submitted to the hotplate test. Values were expressed as mean \pm SEM $(n=6)$. Control value indicates the animals injected with vehicle and the asterisks denote the significance levels when compared with control groups $(p>0.05)$ 


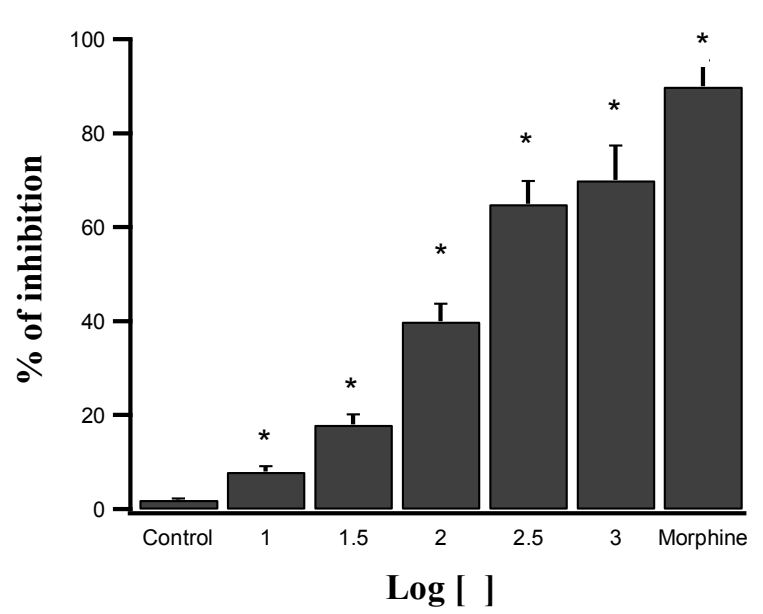

Figure 2: Effects of EOGT and morphine administration against acetic acid-induced writhing response in rats. Each column represents the mean of 6 animals and the error bars indicate the SEM. Control value indicates the animals injected with vehicle and the asterisks denote the significance levels when compared with control groups $(p>0.05)$.

\section{Effect of EOGT on formalin-induced nociception}

The results in Fig. $3 \mathrm{~A}$ and $\mathrm{B}$ demonstrate that EOGT $(10,31.6,100,361$ and $1000 \mathrm{mg} / \mathrm{kg}$, orally) significantly inhibited both the early (neurogenic, 0-5 min) and late (inflammatory, 15-30 min) phases of formalin-induced licking compared with control rats. However, its antinociceptive effects were significantly more pronounced against the second (late) phase of this pain model. The calculated $I D_{50}$ value for the first and second phases (respectively) were: 65.3 \pm 2.6 and $85.1 \pm 3.8 \mathrm{mg} / \mathrm{kg}$, and the inhibitions observed were $58.1 \pm 5.3 \%$ and $69.7 \pm 6.9 \%$ at a dose of $1000 \mathrm{mg} / \mathrm{kg}$, for the first and second phases, respectively (Fig. $3 \mathrm{~A}$ and $\mathrm{B}$ ). The percentage inhibitions of licking produced by morphine $(5 \mathrm{mg} / \mathrm{kg}$, i.p.) were $90.1 \pm 7.5$ and

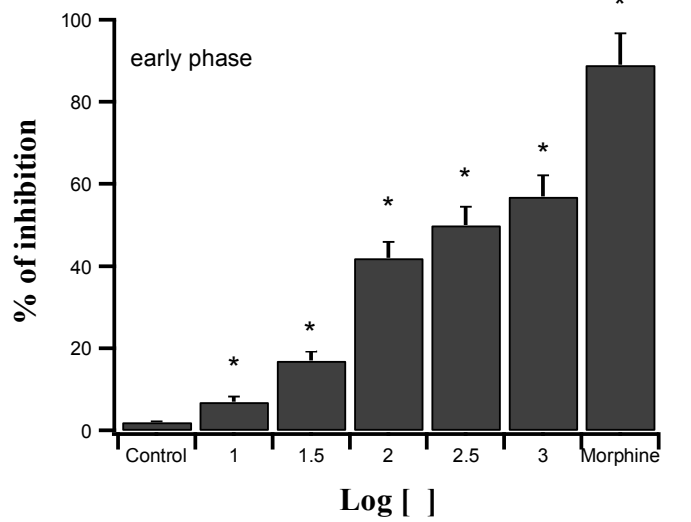

$86.2 \pm 4.4 \%$, for the first and second phases, respectively.

\section{Possible mechanisms of antinociceptive action of Gundelia tournefortii}

Pretreatment of animals with antagonists glienclamide and yoimbina partially reversed the antinociceptive action of EOGT (Table 2). However, there was no reversal when the animals were pretreated with the naloxone and L-NAME (Table 2).

\section{DISCUSSION}

To date, several studies have been performed to investigate possible antinociceptive activities of medicinal plants. In the current study the antinociceptive activity of Gundelia tournefortii essential oil has been studied. Our data demonstrated that the EOGT elicited effective antinociceptive effects in rats as determined by acetic acid-induced abdominal writhing, formalin test and hot plate test. The experimental models used in this study were selected such that both centrally and peripherally mediated effects were measurable. The acetic acid-induced abdominal writhing elucidates peripheral effects; hot-plate test reveal central activity, while the formalininduced nociception test investigate both central and peripheral effects. We also used selective antagonists of several mediators involved in the nociception in an attempt to provide some insight into the mechanisms involved in EOGT antinociceptive properties.

The hot-plate test is widely used for the evaluation of centrally acting analgesics material. In this test the behavioral responses as jumping, licking paws, pulling out of the paws can be measured in terms of their reaction times [19].

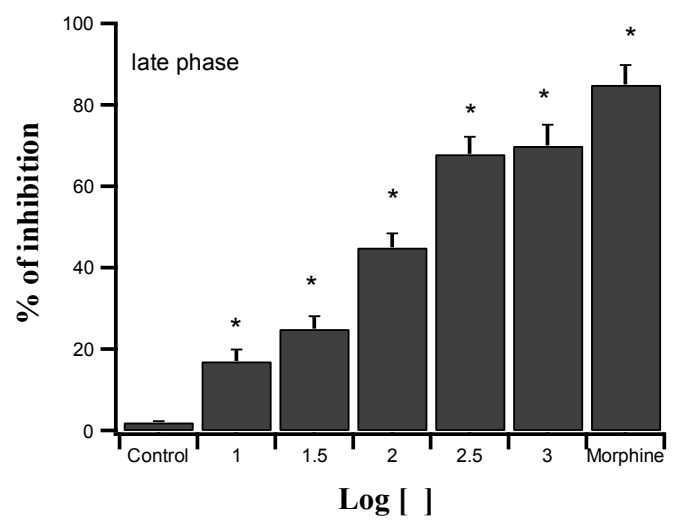

Figure 3: Effects of EOGT $(10,31.6,100,361$ and $1000 \mathrm{mg} / \mathrm{kg})$ and morphine $(5 \mathrm{mg} / \mathrm{kg})$ administration on nociceptive responses to intraplantar injection of formalin in rats. Control values indicate vehicle administration, and the asterisks denote significance levels when compared with the control group $(p>0.01)$. Values were expressed as mean $\pm \operatorname{SEM}(n=6)$ 
Table 2: Effect of naloxone, glibenclamide, yoimbina and L-NAME on EOGT antinociceptive activity in rats assessed using the hot-plate test, abdominal writhing test and formalin-induced pain test. Control indicates vehicle administration, and the one asterisk $\left(^{*}\right)$ denotes significance levels when compared with the control group. Two asterisks $\left({ }^{* *}\right)$ denote significance levels when compared with the EOGT treated group $(p>0.01)$. Values were expressed as mean $\pm \operatorname{SEM}(n=6)$

\begin{tabular}{lcccc}
\hline Treatment & $\begin{array}{c}\text { Increase in } \\
\text { baseline } \\
\text { (hotplate test, \%) }\end{array}$ & $\begin{array}{c}\text { Inhibition (\%) of } \\
\text { licking (Phase I) }\end{array}$ & $\begin{array}{c}\text { Inhibition of } \\
\text { licking (\%) } \\
\text { (Phase II) }\end{array}$ & $\begin{array}{c}\text { Inhibition of } \\
\text { abdominal } \\
\text { writhing (\%) }\end{array}$ \\
\hline Control & $2.3 \pm 0.2$ & $2.1 \pm 0.5$ & $1.6 \pm 0.2$ & $2.2 \pm 0.3$ \\
EOGT & $49.1 \pm 1.7^{*}$ & $50.1 \pm 2.5^{*}$ & $50.4 \pm 3.1^{*}$ & $51.1 \pm 2.7^{*}$ \\
Morphine & $84 \pm 3.5^{*}$ & $88 \pm 2.3^{*}$ & $87 \pm 3.2^{*}$ & $86 \pm 2.4^{*}$ \\
Naloxone & $2.1 \pm 0.4$ & $1.4 \pm 0.7$ & $2.2 \pm 0.7$ & $5.1 \pm 0.8$ \\
Naloxone + EOGT & $49.3 \pm 1.8$ & $52.1 \pm 2.1$ & $50.1 \pm 2.2$ & $51.7 \pm 1.3$ \\
Morphine +NaloxOne & $3.4 \pm 1.5$ & $4.5 \pm 1.3$ & $2.8 \pm 1.6$ & $3.5 \pm 1.1$ \\
Glienclamide & $2.1 \pm 0.1$ & $1.9 \pm 1.5$ & $1.7 \pm 0.3$ & $2.0 \pm 0.2$ \\
Glienclamide+ EOGT & $12.7 \pm 2.4^{* *}$ & $14.2 \pm 3.3^{* *}$ & $13.9 \pm 4.1^{* *}$ & $10.5 \pm 1.9^{* *}$ \\
Yoimbina & $2.2 \pm 0.4$ & $2.0 \pm 0.1$ & $1.8 \pm 0.5$ & $1.9 \pm 0.4$ \\
Yoimbina+ EOGT & $17.2 \pm 3.1^{* *}$ & $14.5 \pm 2.2^{* *}$ & $11.1 \pm 2.3^{* *}$ & $15.7 \pm 4.5^{* *}$ \\
L-NAME & $2.4 \pm 0.2$ & $1.7 \pm 0.5$ & $2.1 \pm 0.7$ & $2.4 \pm 0.8$ \\
L-NAME+ EOGT & $45.1 \pm 3.4$ & $49.1 \pm 4.5$ & $47.1 \pm 6.4$ & $50.9 \pm 5.2$ \\
\hline
\end{tabular}

Doses of EOGT used were those used to give $\mathrm{ID}_{50}$

Comparing values obtained for reaction time (licking time) of animals treated with EOGT extract and the control values both before and after treatment, it is clear that the EOGT extract caused a significant dose-dependent prolongation of latency times which indicates centrally mediated activity.

The writhing test has long been used as a screening tool to evaluate antinociceptive properties of new substances [20,21]. In the writhing test, acetic acid activates peripheral nociceptors on the sensory nerve fibers by releasing pro-inflammatory substances. The nociceptive response in the acetic acid-induced abdominal constriction assay arises from synthesis of prostaglandins by the action of the constitutively expressed enzyme cyclooxygenase-2 (COX-2), which leads to hyperalgesia and pain. Non-steroidal antiinflammatory drugs like aspirin inhibit synthesis of prostaglandin resulting in the decrease sensitivity of the nociceptors to pain producing agents such as bradykinin. In this study EOGT at test doses $(10,31.6,100,316$ and $1000 \mathrm{mg} / \mathrm{kg}$, orally) caused a significant dose-dependent decrease in the number of acetic acid-induced writhes in rat in comparison to control. This observation indicates that EOGT possesses peripherally-mediated antinociceptive property and EOGT induced analgesic effect through mechanism linked partly to inhibition of prostaglandin synthesis.

The formalin test identifies mainly centrally acting agents which inhibit both early and late phases almost equally. Injection of formalin induces a biphasic pain response; the first phase (short phase) is thought to result from direct activation of C-fiber afferent nociceptors. After a short period, the acute phase is followed by a continuous prolonged response (Phase II) which is due to the combined effects of afferent input and central sensitization in the dorsal horn. A central sensitization of dorsal horn neurons occurs during inflammatory pain, In that phase amines (histamine and serotonin), prostaglandins, bradykinin and cytokines (e.g., TNF-a, IL-1b, IL-8) play the major role [22,23]. Suppression of both phases of nociception as observed with the EOGT extract in this study lends strong credence to the presence of both centrally and peripherally mediated effects. This speculation of dual activity is further buttressed by the significant activity observed in both the acetic acid-induced abdominal writhing and hotplate tests.

The mechanisms by which the EOGT produced antinociception in the three models of nociception studied are not completely understood. The present results show, however, that EOGT acts partially by interaction with potassium channels sensitive to ATP and $\alpha 2$ adrenergic receptor, because the antagonists glibenclamide (potassium channels sensitive to ATP antagonist) and yoimbina ( $\alpha 2$ adrenergic receptor antagonist) partially reduced EOGT antinociceptive activity when assessed against hot-plate test, abdominal writhing test and formalin-induced pain test. These results are consistent with several recent studies such as Abotsi et al [24]. Activation of opioids receptors is also important in modulating pain. Agonist of these receptors have significant antinociceptive effect that can be reversed by non-selective opioid receptor antagonist naloxone. However, this mechanism does not participate in EOGT 
activity, because pretreatment animals with this non-selective opioid receptor antagonist naloxone did not reverse its. Another important pathway in modulation of nociception is the pathway for nitric oxide. In this regards, pretreatment with an inhibitor of nitric oxide synthase (L-NAME) $15 \mathrm{~min}$ before experiment, did not reverse the antinociception caused by EOGT. This observation suggests that nitric oxide pathway had no effect. Further study needs to understand the precise receptor (such as TRPV1 receptors, protein kinase $\mathrm{C}$ and others) participate in analgesic effect of EOGT.

The antinociceptive effect of EOGT may be related to the presence of a number of constituents such as eugenol, p-cyme, $\beta$ caryophyllene, and estragole in the essential oil extract. For example eugenol the major essential oil of Gundelia tournefortii $(9.5 \%)$ has been shown to possess anti-inflammatory, antioxidant, anaesthetic and muscle relaxant properties [25]. Previous study showed that eugenol exhibits antinociceptive effects through different mechanisms that may involve both central and peripheral pathway, One of these mechanisms, is via blockade of calcium channels and vanilloid receptor modulation [26]. Further study done by Dal Bó et al [27] proved that eugenol promotes significant antinociception by the inhibition of glutamatergic neurotransmission and cytokine signaling. A study done by Santana et al [28] showed that p-cymene (one of the principal compounds of essential oil of Gundelia tournefortii) possesses peripheral and central antinociceptive properties as well as antiinflammatory activity and they suggest that pcymene act on the arachidonic acid cascade and/or modulation of the production of proinflammatory molecules.

\section{CONCLUSION}

The present findings indicate that EOGT has analgesic effect arising from both CNS and peripheral actions and is related to its ability to activate potassium channels sensitive to ATP and $\alpha 2$ adrenergic receptors. Further studies are in progress to elucidate the precise mechanisms of action.

\section{DECLARATIONS}

\section{Acknowledgement}

The authors are grateful to Hashemite University and American University of Madaba for providing the facilities and financial support to conduct this study.

\section{Conflict of Interest}

No conflict of interest associated with this work.

\section{Contribution of Authors}

The authors declare that this work was done by the authors named in this article and all liabilities pertaining to claims relating to the content of this article will be borne by them.

\section{REFERENCES}

1. Lev $Y$, Abbo S. Traditional use of A'kub (Gundelia tournefortii, Astreraceae) in Israel and the Palestinian Authority area. Econ Bot 1999; 53: 217-219.

2. Halabi S, Battah A, Aburjai T, Hudaib M Phytochemical and Antiplatelet Investigation of Gundelia tournifortii. Pharm Biol 2005,43: 496-500.

3. Jarald E, Joshi S, Jain D. Diabetes and herbal medicines. Iran. J Pharmacol therapeutics 2008; 7: 97-106.

4. Jamshidzadeh $A$, Fereidooni F, Salehi Z. Hepatoprotective activity of Gundelia tourenfortii. J Ethnopharmacol 2005; 101(1-3): 233-237.

5. Coruh N, Celep A, Ozgokce F, Iscan M Antioxidant capacities of Gundelia tournefortii $L$. extracts and inhibition on glutathione-S-transferase activity. Food Chem 2007; 100: 1249-1253.

6. Samani M, Kopaei M, Azimi N. Gundelia: A Systematic Review of Medicinal and Molecular Perspective. Pakistan J Biol Sci 2013; 16(21): 1238-1247.

7. Sezik E. Traditional medicine in Turkey. J Ethnopharmacol 2001; 75: 95-115.

8. Hildebert $W$, Hubertus $N$, Aynehchi Y. Molluscicidal saponins from Gundelia tournefortii. Phytochem 1984; 23(11): 2505-2508.

9. Rehana Banu H, Nagarajan N. GC-MS determination of bioactive components of Wedelia chinensis (Osbeck) Merrill. J. Chem. Pharm. Res. 2013; 5(4): 279-285.

10. Bagci E, Hayta S, Kilic O. Essential Oils of Two Varieties of Gundelia tournefortii L. (Asteraceae) from Turkey. Asian. J. Chem. 2010; 22 (8): 6239-6244.

11. Azeez O, Kheder A. Effect of Gundelia tournefortii on some biochemical parameters in dexamethasoneinduced hyperglycemic and hyperlipidemic mice. Iraqi. J. Vet. Sci. 2012; 26: 73-79.

12. Ozkan A, Yumrutas $O$, Saygideger $S$, Muhittin $K$. Evaluation of Antioxidant Activities and Phenolic Contents of Some Edible and Medicinal Plants from Turkey's Flora. Adv. Environ. Biol. 2011; 5(2): 231-236.

13. Asgary S, Movahedian A, Badiei A, Hamidzadeh Z. Effect of Gundelia tournefortii $L$ on some cardiovascular risk factors in animal model. J. Med. Plants. 2008; 28:112119.

14. Siani A, Garrido I, Monteiro S, Carvalho E, Ramos M. Protium icicariba as a source of volatile essences. Biochem. Syst. Ecol. 2004; 32: 477-489. 
15. Zimmermann M. Ethical guidelines for investigation of experimental pain in conscious animals. Pain. 1983; 16 . 109-110.

16. Qnais E., Abu diehey M, Abdalla S. The antinociceptive and anti-inflammatory effects of Salvia officinalis leaf aqueous and butanol extracts. Pharm. Boil. 2010; 48(10): 1149-1156.

17. Matheus M, Berrondo L, Vieitas E, Menezes F, Fernandes $P$. Evaluation of the antinociceptive properties from Brillantaisia palisotii Lindau stems extracts. J. Ethnopharmacol. 2005; 102:377-381.

18. Lorke D. A new approach to practical acute toxicity testing. Arch. Toxicol.1983; 54:275-287.

19. Le Bars D, Gozariu M, Cadden S. Animal Models of Nociception. Pharmacol. Rev. 2001; 53: 597-652.

20. Hunskaar $S$, Hole $K$. The formalin test in mice: dissociation between inflammatory and noninflammatory pain. Pain. 1987; 30 (1): 103-104.

21. Tjolsen A, Berge O, Hunskaar S. Rosland J. Hole K. The formalin test: an evaluation of the method. Pain. 1992; 51(1): 5-17.

22. Granados-Soto V, Alonso-López R, Asomoza-Espinosa $R$, Rufino M., Gomes- Lopez L, Ferreira S. Participation of COX, IL-1 beta and TNF alpha in formalin-induced inflammatory pain. Proc West Pharmacol Soc. 2001; 44: 15-17.
23. Santos A, Calixto J. Further evidence for the involvement of tachykin inreceptor subtypes in formalin and capsaicin models of pain in mice. Neuropeptides 1997; 31(4): 381-389.

24. Abotsi W, Ainooson G, Owusu G, Wood E, AmohBarimah A,. Analgesic effects of stem bark extracts of Trichilia monadelpha (Thonn.) JJ De Wilde. Indian Journal of Pharmacology 2012; 44( 6): 765-773.

25. Sayyah M, Saroukhani G, Peirovi A. Kamalinejad M. Analgesic and anti-inflammatory activity of the leaf essential oil of Laurus nobilis Linn. Phytother. Res.2003; 17(7): 733-736.

26. Kurian R, Arulmozhi DK, Veeranjaneyulu A, Bodhankar S. Effect of eugenol on animal models of nociception. Indian. J. Pharmacol. 2006; 38: 341-345.

27. Dal Bó W, Luiz A, Martins D, Mazzardo-Martins L, Sentos A. Eugenol reduces acute pain in mice by modulating the glutamatergic and tumor necrosis factor alpha (TNFa) pathways. Fundam Clin Pharmacol. 2013; 27(5): 517525.

28. Santana F, Quintans-Júnior J, Cavalcanti $H$, Oliveira G, Guimaraes G, Cunha S, Melo S, Santos V, Araujo A, Bonjardim L. p-Cymene reduces orofacial nociceptive response in mice. Brazil J Pharmacog. 2011; 21(6): 1138-1143. 